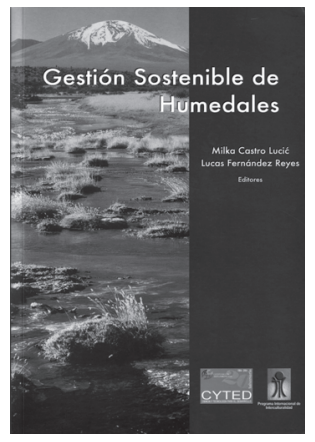

\title{
Milka Castro Lucić y Lucas Fernández Reyes (Editores). Gestión Sostenible de Humedales
}

\author{
Santiago de Chile: Programa Iberoamericano de \\ Ciencias y Tecnología para el Desarrollo (CYTED), El \\ Centro del Agua para Zonas Áridas y Semiáridas de \\ América Latina y el Caribe (CAZALAC) y Programa \\ Internacional de Interculturalidad, Universidad de \\ Chile, 2007, 409 p.
}

\section{Valentina Olivares ${ }^{1}$}

Los humedales son ecosistemas que cumplen numerosas funciones ambientales, la más importante de todas es ser un reservorio de agua y albergue de una gran biodiversidad. Estos ecosistemas también entregan beneficios al hombre, de tipo económico, social y cultural, ya que permiten el desarrollo de las actividades pesqueras y agrícolas, abastecen de agua a las comunidades cercanas, permiten la explotación del recurso energético (turba y leña) y son un espacio para la recreación y el turismo (Convención de Ramsar, 1996).

Los humedales están presentes en todo el mundo como una consecuencia de las características climáticas y topográficas del lugar donde se encuentran. Son sistemas altamente complejos y muy vulnerables a los cambios que se generan en el medio ambiente.

La actividad humana es uno de los principales responsables de la degradación de estos ecosistemas. La excesiva productividad agrícola y ganadera, el cambio de uso de suelos, la contaminación de aguas y riberas, la caza de fauna nativa y la extracción de especies vegetales, son algunas de las acciones que ponen en constante peligro la existencia de los humedales.

\footnotetext{
1 Estudiante de Geografía que cursa su último año de carrera. E-mail: volivar1@uc.cl
}

Sin embargo, hoy en día existe una creciente preocupación por parte de los gobiernos, centros de investigación y organizaciones no gubernamentales (ONGs), para recuperar y conservar humedales, generando normativas y planes de gestión sustentables en estos lugares. Iberoamérica, y en especial América del Sur, presentan una vasta superficie de humedales y cuentan con una amplia variedad de estos, motivo por el cual es necesario abordar este tipo de problemática.

El año 2007 se publicó el libro "Gestión Sostenible de Humedales", editado por Milka Castro Lucić y Lucas Fernández Reyes. Esta publicación tuvo el apoyo del Programa Iberoamericano de Ciencias y Tecnología para el Desarrollo (CYTED), el Centro del Agua para Zonas Áridas y Semiáridas de América Latina y el Caribe (CAZALAC) y el Programa de Interculturalidad de la Universidad de Chile. Esta obra es el resultado de una recopilación de casos de estudio de humedales en Iberoamérica, especialmente en América del Sur (Chile, Argentina, Bolivia, Colombia y Venezuela); es la expresión gráfica de los logros alcanzados por la Red Iberoamericana de Humedales, del programa CYTED, que busca difundir y actualizar los conocimientos respecto a la gestión sostenible de humedales en la región.

El libro se encuentra dividido en tres grandes temas. El primero de ellos corres- 
ponde a estudios que tienen relación con la gestión y manejo sustentable de humedales. En esta sección se presentan trece investigaciones que abarcan diversos temas, tales como lagunas urbanas, turberas, humedales de puna, patagónicos y altoandinos, entre otros. A pesar de la heterogeneidad de las investigaciones presentadas, todas se enfocan a mejorar la gestión de los humedales, ya sea mediante acciones, lineamientos, normativas, participación, y organización de la ciudadanía y de las autoridades. El estudio "Hacia la gestión de lagunas urbanas: la experiencia en la laguna Alalay (Cochabamba-Bolivia)", es un ejemplo de lo mencionado anteriormente. La acción del hombre en la laguna Alalay ha causado el deterioro progresivo de esta. Las consecuencias de la eutrofización antrópica de la laguna han movilizado a las autoridades locales en conjunto con diversos centros de investigación, para elaborar un plan de conservación y manejo, que sea a futuro un instrumento normativo, que permita orientar el accionar de las autoridades y de la ciudadanía.

El segundo tema del libro corresponde a casos de estudio que tienen relación con la gestión, valoración económica y legislación de los humedales. En esta sección se presentan siete estudios referidos a la ausencia o presencia de legislación y las relaciones de productividad y sustentabilidad de los humedales, es decir, el aprovechamiento racional de los recursos y beneficios que entregan estos espacios, sin perjudicar su potencial.

Un ejemplo claro de valoración económica, gestión y sustentabilidad ambiental es el estudio "Importancia económica de los Bofedales en la producción de fibra de alpaca en la comunidad de Caripe, Parque Nacional Sajama" (Bolivia). La producción de fibra de camélidos en este parque nacional es el principal ingreso de las comunidades que lo habitan, por ello se ha hecho necesario realizar estudios y coordinar a los actores involucrados para que la actividad económica pueda continuar desarrollándose sin perjudicar los recursos naturales, en especial los bofedales, que son la base de este sistema económico.
Por último, el tercer tema expuesto corresponde a los estudios que tienen relación con los humedales y la biodiversidad. En esta sección se presentan diez investigaciones que dan cuenta de la relación que existe entre las actividades humanas y las especies animales y vegetales que habitan estos ambientes. Algunos de los temas expuestos son: la diversidad vegetal, la degradación de los ecosistemas y las funciones de estos espacios. El estudio "Pérdida de hábitat por actividades antrópicas en las marismas y planicies de marea del estuario del río Gallegos (Patagonia Austral, Argentina)" muestra la constante amenaza que sufren las especies que habitan dichos humedales. En este caso la expansión de la ciudad Río Gallegos sobre los frágiles ecosistemas intermareales ha modificado la superficie y biodiversidad del lugar, afectando especialmente a las aves playeras migratorias que allí habitan.

\section{Consideraciones finales}

Es necesario destacar la importancia de la divulgación de investigaciones relacionadas a "humedales", en el sector público, para que en la toma de decisiones se consideren las funciones que estos ejercen y los beneficios que aportan al medio ambiente. También se debe enfatizar el rol que cumplen los ciudadanos en la conservación de los humedales, ya que su gestión facilita la protección y agiliza la recuperación de estos espacios, por ello hay que informar y culturizar a la población. Esta última idea adquiere mayor importancia en los países que presentan un mayor número, variedad y superficie de humedales en su territorio, como es el caso de muchos países Iberoamericanos.

\section{Referencias bibliográficas}

DAVIS, T. J.; BLASCO, D. \& CARBONELL, M. (Preparadores). Manual de la Convención de Ramsar: Una Guía a la Convención sobre los Humedales de Importancia Internacional. España: Ministerio de Medio Ambiente, 1996. 